\title{
MEASURING THE TOTAL FACTOR PRODUCTIVITY OF THE PORTUGUESE WATER AND SEWERAGE SERVICES
}

\author{
Rui Cunha Marques ${ }^{\S}$
}

\begin{abstract}
RESUMO
A reduzida produtividade dos serviços de água e de saneamento tem justificado as dificuldades que os operadores destas entidades têm em melhorar a qualidade de serviço e em aumentar o seu grau de cobertura. Melhorar a produtividade constitui, portanto, uma das melhores formas de proteger os interesses dos consumidores. Este artigo apresenta um estudo empírico que determina a produtividade total dos fatores dos serviços de água e de saneamento portugueses. Os resultados obtidos são aqui apresentados e discutidos, evidenciando a reduzida produtividade deste setor em Portugal e realçando que os operadores privados e mais rurais são aqueles que apresentam maiores valores de produtividade.
\end{abstract}

Palavras-chave: produtividade total dos fatores, números-índice, índice de produtividade de Malmquist, serviços de água e de saneamento.

\begin{abstract}
The poor productivity in the water and sewerage services (WSS) has been a justification for the difficulties these entities face when trying to expand the service coverage, enhance the quality of service and reduce the cost of service. Improving the WSS productivity is, therefore, one of the best ways of protecting the customers' interests. This article presents an empirical study that computes the total factor productivity (TFP). It stresses the results obtained and discusses them, proving the low productivity of this sector in Portugal and pointing to the conclusion that the private and the rural WSS are the most productive ones.
\end{abstract}

Keywords: total factor productivity, index numbers, Malmquist productivity index, water and sewerage services.

JEL classification: C14, D24, L95.

$\S$ Assistant Professor, CESUR, IST, Technical University of Lisbon. Contact address: Avenida Rovisco Pais, 1049-001. Lisbon, Portugal. E-mail: rcmar@civil.ist.utl.pt.

Recebido em abril de 2007. Aceito para publicação em maio de 2008. 


\section{INTRODUCTION}

Productivity is defined as the relationship between the outputs produced and the inputs consumed. Total factor productivity (TFP) computes the change in all the outputs relative to the change in the usage of all the inputs for a given time period and organization. It has been employed in several sectors, such as utilities, transport, agriculture, banking, health and education. In the utilities, the majority of the studies published regard the energy and telecommunications. The water and sewerage services (WSS), traditionally managed by the public sector, have not shown much concern with their productivity. However, this circumstance has been progressively changing, especially over the last decade, due to a larger participation of the private sector, more demanding quality of service requirements, tighter macroeconomic policies and the value for money growing importance, mainly in the services of general economic interest. Computing the TFP in the WSS has different aims, namely:

- identification of the most efficient and innovative WSS that are reference peers (best practices);

- creation of a competitive environment among the WSS;

- setting the economic regulation core when performance based regulatory methods are adopted;

- analysis of the market structure with regard to the optimal company size, ownership and mode of organization (e.g. corporatization).

Over the past years, a great deal of TFP studies have been developed by regulators who have the efficiency and productivity promotion as one of their main tasks. This is also one of the reasons that justify the reduced number of productivity computation studies covering the WSS due to the lack of specific regulation (economic) in this sector in many countries. The works of Steering Committee (1992), Glaser (1993), Manning and Molineux (1993), ACT (1995), Crampes et al. (1997), Ancarani (2000), Ashton (2000), Parker and Saal (2001), Estache and Kouassi (2002), Nakayama (2002), Woodbury and Dollery (2003), Europe Economics (2003), London Economics et al. (2003), Estache and Trujillo (2003), Stone \& Webster Consultants (2004), Saal and Parker (2004), Seroa da Motta and Moreira (2004), Nera (2004), Saal and Parker (2005), Coelli and Walding (2005), Lin (2005) and Harchaoui and Dachraoui (2005) are some exceptions. Indeed, there is no logical explanation to prevent the accomplishment of this kind of studies within the WSS. Quite on the contrary, this sector works in a natural monopoly context, therefore, it encourages the "quiet life" and inefficiency. Besides, the WSS are not liberalized in most of the countries and in the remaining (England and Wales) the positive effects of their liberalization are likely to be few. In addition, these utilities provide essential services to the citizens, the society and the environment. Thus, a sound management and the resources available to these industries should overlap all the other existing interests in order to provide incentives to innovation and to performance improvement at an appropriate scale.

This research computes the TFP of the Portuguese WSS between 1994 and 2001 in two different ways. Section 2 describes the Portuguese water sector. Afterwards, the TFP concept is introduced. Then, in Section 4, the index numbers technique is briefly examined and empirically 
applied. Section 5 analyses, decomposes and applies the Malmquist productivity index (MPI) and stresses the results attained. Section 6 discusses the results according to the technique and the explanatory factors adopted and some policy considerations are made. Finally, Section 7 presents the main conclusions.

\section{The Water SeCtor IN PoRTUgal}

In Portugal, except for Lisbon, the WSS management responsibility belonged, until the 1990s, exclusively to the municipalities. Since 1993 legal basis has been provided for private sector participation. According to the law there are two kinds of water systems, respectively the multimunicipal systems ("bulk" or wholesale segment) and the municipal systems (distribution or retail segment). The multimunicipal systems are those that provide "bulk" water to, at least, two municipalities and that require a predominant investment by the State for reasons of national interest. All the remaining structures are called municipal systems, even though they are managed by municipal associations. This law includes the possibility of direct operation and management by the State of the multimunicipal systems, and by the municipalities or their associations of the municipal systems. It also allows the concession by the State (without competitive bidding) of the operation and management of the multimunicipal systems to a public company or companies with a major public capital shareholding, and the concession by the municipalities (if subject to public tender) of the municipal systems management and operation to any company irrespective of capital shareholder or to users associations. In 1998, the creation of municipal companies became possible according to three frameworks, correspondingly one municipality, more than one municipality (intermunicipal company) and one or more municipalities with a private partner (mixed company) with minor shareholding, though the latter is subject public bidding. The water supply to Lisbon was, until the 1970s, provided by a private company which was, at that point in time, replaced by a public company (EPAL) belonging to the State, a situation that remains today.

With the reforms of the water sector the priority of the government was to set a sector-specific regulatory authority for the WSS (and the solid waste). Hence, the Institute for the Regulation of Water and Waste (henceforth IRAR) was created in 1997 and in the next year its statutes were approved. The objectives of IRAR were to ensure the quality of the services provided, to supervise the financial equilibrium and sustainability of the sector under the terms of its statutes and the law. After a period characterized by a weak leading role, since 2003, when a new Board of Directors was nominated, IRAR has adopted a different behavior. The plans of action are now formulated at the structural regulation level and at the operators' behavior level (conduct regulation). In the first case the functions refer to the definition and consolidation of the market structure as well as to its strengthening. In the second, the aspects that should be regulated deal with the behavior of the operators, mostly with the prices and the quality of service, that is, the so-called economic regulation. The main tool used in the quality of service regulation (and also in price regulation) is the comparison of a performance indicators set applied to each operator followed by its public display (sunshine regulation). 
Currently the coverage level of water supply in Portugal is close to $95 \%$ while for the sewerage services the percentage is about $85 \%$ ( $70 \%$ for the sewage treatment). The quality of service is high and the water quality parameters comply with the EU legislation. The water resources levels of pollution have decreased significantly in the last years. However, the price of water has been rising and it is expected to rise even more. The main challenge the water sector will have to face in the following years is certainly that of efficiency and productivity earnings and, consequently, the value for money.

Finally, another relevant issue which certainly characterized the last decade in Portugal was the water sector growing trend towards corporatization. Not only has private sector participation increased, with about two tens of operators, representing $30 \%$ of the population in December 2006, provided by private companies, but municipal companies have also been spreading out in these sectors. In December 2006 there were already almost 20 municipal companies covering roughly $15 \%$ of the Portuguese population. Notice that in Portugal there are about 300 water utilities. The present research includes the major water utilities of Portugal, encompassing all private companies, municipal companies and municipal services with autonomy. The remaining water services are managed directly by the municipalities and in general they have a small size and do not have separate accounts.

\section{Total Factor Productivity (TFP)}

TFP, which has been defined as the actual outputs increase, not explained by the inputs increase, is an extension to the partial productivity measure concept, including all the inputs and outputs. Hence, TFP will be the ratio between the sum of all the weighted outputs (y) and the sum of all the weighted inputs (x), as shown by (1), where $\mathrm{M}$ and $\mathrm{N}$ represent the outputs and the inputs total number, and $\mathrm{a}_{\mathrm{i}}$ and $\mathrm{b}_{\mathrm{j}}$ are the outputs and the inputs weights, respectively.

$$
T F P=\frac{\sum_{i=1}^{M} a_{i} y_{i}}{\sum_{j=1}^{N} b_{j} x_{j}}
$$

The TFP index computes the change in all the outputs by the change in the inputs consumption in a given time period. If the output index grows faster than the input index, the TFP change is positive and there is progress, otherwise, if the change is negative, we are before regression.

TFP change is often decomposed into technical efficiency change (TEC), production technology change (PTC) and scale efficiency change (SEC). In the case of multiple inputs and outputs the allocative efficiency component is also relevant. Moreover, in the empirical world there are other factors that can explain the TFP change, like the ones that modify the WSS operational or 
institutional environment. Abramovitz (1956) refers to the TFP as a «measure of our ignorance», owing to the several obscure hypotheses that might justify its change.

The TFP computation methods are classified according to two criteria. On the one hand, the classification depends on whether they are frontier or non-frontier methods and, on the other, if the techniques used are parametric or non-parametric. ${ }^{1}$ The frontier methods are based on the best practices to the detriment of the average adjustment. Their main benefit is the fact that they enable the TEC determination in opposition to the non-frontier methods which assume a WSS optimized behavior. The parametric techniques specify a functional form for the production technology, while the non-parametric ones do not include any explicit estimation of functions.

\section{INDEX NUMBERS}

\subsection{Concept, examples and TFP measurement}

An index number concerns the relation between two states of a certain dimension possible to change in time, space, or both. Its calculation describes the intensity of a phenomenon with regard to the one that had been measured in a given period (or space) adopted as reference, called base period. The indexes are used to measure quantity and price changes over time, as well as their differences between WSS.

The index numbers studies estimate the TFP as the ratio between an output index and an input index. As the WSS have, almost always, multiple inputs and outputs, it is necessary to aggregate them in order to obtain a single input index and a single output index. This aggregation is accomplished by the indexes construction, corresponding to the weighted sums of the individual inputs and outputs. The weights used generally concern the output revenues, while the input index weights are those of the input costs, in case the quantity indexes are being determined. If we want to calculate the price indexes, we use the quantities as weighting measures.

The non-parametric non-frontier technique based on index numbers is simple and easy to apply, requiring a single WSS. The results are also transparent and objective. However, the index numbers do not enable the productivity decomposition, only take into account the WSS under analysis and demand elements about the input and output quantities and prices.

Among the most used index numbers we can find the Laspeyres, Paasche, Fisher and Törnqvist indexes. Their usage assumes either the price or quantity calculation if these elements change in a given period (or space), or the input and output computation if the change occurs in the input and output prices and quantities.

In the TFP study two situations are distinguished, one relating to binary comparisons, which enables the TFP computation for two periods (or WSS) and the other referring to multilateral

1 See, for more details about TFP computation methods, Grosskopf (1993) and Färe et al. (1998). 
comparisons, involving more than two periods (or WSS). Generally, the Törnqvist indexes are employed in the TFP calculation although the Fisher indexes are equally a good solution. ${ }^{2}$

\subsection{Case-study}

The index numbers technique was adopted to calculate the TFP of 56 WSS between 1994 and 2001, covering about $57 \%$ of the Portuguese population. The period of 8 years considered was characterized by deep changes in the water sector, to which the enactment of new regulation and the European Union funds largely contributed. The latter allowed for a high volume of investments, increasing the coverage level as well as its reorganization with the creation of multimunicipal companies for bulk water and sewage interception and treatment. At the same time, the quality of service improved to a great extent and a culture of customer service was instituted, which was limited or almost non-existent until then. The sample here analyzed comprises all the private and municipal companies and all the municipal services with autonomy. The small municipal services without autonomy were not included in the sample because no data were available.

\subsubsection{Data collection}

In Portugal, the statistical information relative to the WSS is scarce and not easily available. These services are highly fragmented and there is no bureau to compile the data. Nevertheless, the information needed for the TFP calculation is, as a rule, available in the WSS account reports published annually. For that reason, authorization was requested to consult those documents. ${ }^{3}$ Later, the WSS were inquired about the missing elements. The sample includes 39 municipal services with autonomy, 13 private companies, 3 municipal companies and 1 state company. There are 6 water utilities which provide water supply to more than 250000 inhabitants and only four companies provide water to less than 25000 inhabitants each.

\subsubsection{Models specification}

The TFP model must comprise all the variables at an adequate level of aggregation likely to characterize the production. Besides, they must be quantified and consistent between the different WSS. Thus, for the water services only, the outputs produced should be the revenue water volume and the water customers, while the inputs consumed should be the ones corresponding to the capital and to the operation and maintenance (non-capital) costs. If the water services are also responsible for the sewerage services, the output sewerage service users should be added. Figure 1 shows the WSS production technology. It also presents the explanatory factors likely to justify the WSS performance. Figure 1 could include the volumes of collected and treated sewage as outputs as well. Since these outputs were not computed separately in most of the Portuguese WSS, the option was for its non-integration. ${ }^{4}$ This aggregation can influence slightly the final results as the costs of these different parcels are imputed to the inputs and do not generate revenues.

2 See Diewert (1992). Owing to their properties, the Törnqvist and Fisher indexes are the most used.

3 In Portugal, the right to administrative information is a constitutional principle, therefore the access to these documents cannot be refused.

4 To several WSS the sewerage tariff basket was a non-volumetric one and it seldom considered the sewage treatment. 


\section{Figure 1 - Production technology of WSS}

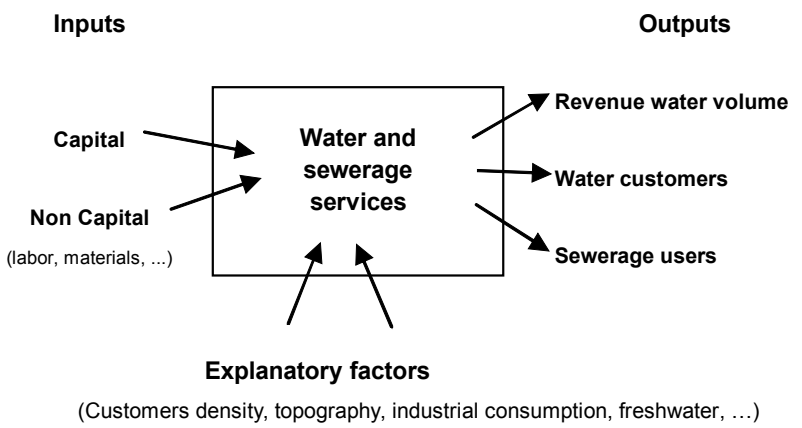

The models used are represented in Table 1 . The outputs are weighted by the corresponding revenues, that is, by the revenues coming from the water sales, by the meter tariff income and the other incomes from the water service (only) and by the income charge from the sewerage service. The inputs are weighted by the respective costs. The input staff includes the number of employees in full time equivalent at the end of each year. The cost of this input is obtained by means of the ratio between the staff costs and the employees' number. The capital is measured through the net assets. Its price is established through the capital cost, obtained by the sum of the depreciation plus the interest expenses, conveyed as a percentage of the net assets. The last of the inputs is the other quantities of operation and maintenance and it is measured through the operation and maintenance costs after deducting the staff costs. This input is weighted by means of a deflator price index that reflects the consumer price index. Both the capital quantities and the other quantities of operation and maintenance are measured in monetary units with 2001 reference prices. For the water service (only), the variables are the same, except for the input sewerage service users which does not exist.

Table 1 - Variables average values for the years 1994 and 2001

\begin{tabular}{|c|c|c|c|c|c|c|}
\hline & \multicolumn{2}{|c|}{1994} & \multicolumn{2}{|c|}{2001} & \multicolumn{2}{|c|}{ Change (\%) } \\
\hline & Quantity & Price & Quantity & Price & Quantity & Price \\
\hline \multicolumn{7}{|l|}{ Outputs } \\
\hline Revenue water volume $\left(\mathrm{m}^{3}\right) ;\left(€ / \mathrm{m}^{3}\right)$ & 5612428 & 0.730 & 6795680 & 0.894 & 21.1 & 22.5 \\
\hline WS customers (no.); [€/(no.xyear)] & 37920 & 29.89 & 47294 & 42.06 & 24.7 & 40.7 \\
\hline SS users (no.); [€/(no.xyear)] & 22254 & 37.89 & 31308 & 70.30 & 40.7 & 85.5 \\
\hline \multicolumn{7}{|l|}{ Inputs } \\
\hline Staff $\left(\mathrm{n} .{ }^{\circ}\right) ;[€ /($ no.xyear) $]$ & 183 & 11111 & 187 & 16968 & 2.2 & 52.7 \\
\hline O\&M other quantities $\left(10^{3} €\right)^{*} ;(-)$ & 2694 & 0.806 & 4316 & 1.000 & 60.2 & 24.1 \\
\hline Capital $\left(10^{3} €\right)^{*} ;(-)$ & 21830 & 0.111 & 33512 & 0.113 & 53.5 & 1.8 \\
\hline
\end{tabular}

* 2001 reference prices; O\&M - Operation and maintenance; WS - water service; SS - sewerage service. 


\subsubsection{Results}

Figure 2 illustrates the TFP average and cumulative values, for each WSS over the period 1994-2001. ${ }^{5}$ The computation was made by means of a spreadsheet and the values presented are the average of the Laspeyres, Paasche, Fisher and Törnqvist indexes. As the sample represents around $57 \%$ of the population, the values obtained correspond to a gross estimation of the WSS TFP change in Portugal over this period. WSS 18, 26 and 47 were considered outliers, as they correspond to particular situations.

Figure 2 - Average and cumulative TFP changes by WSS

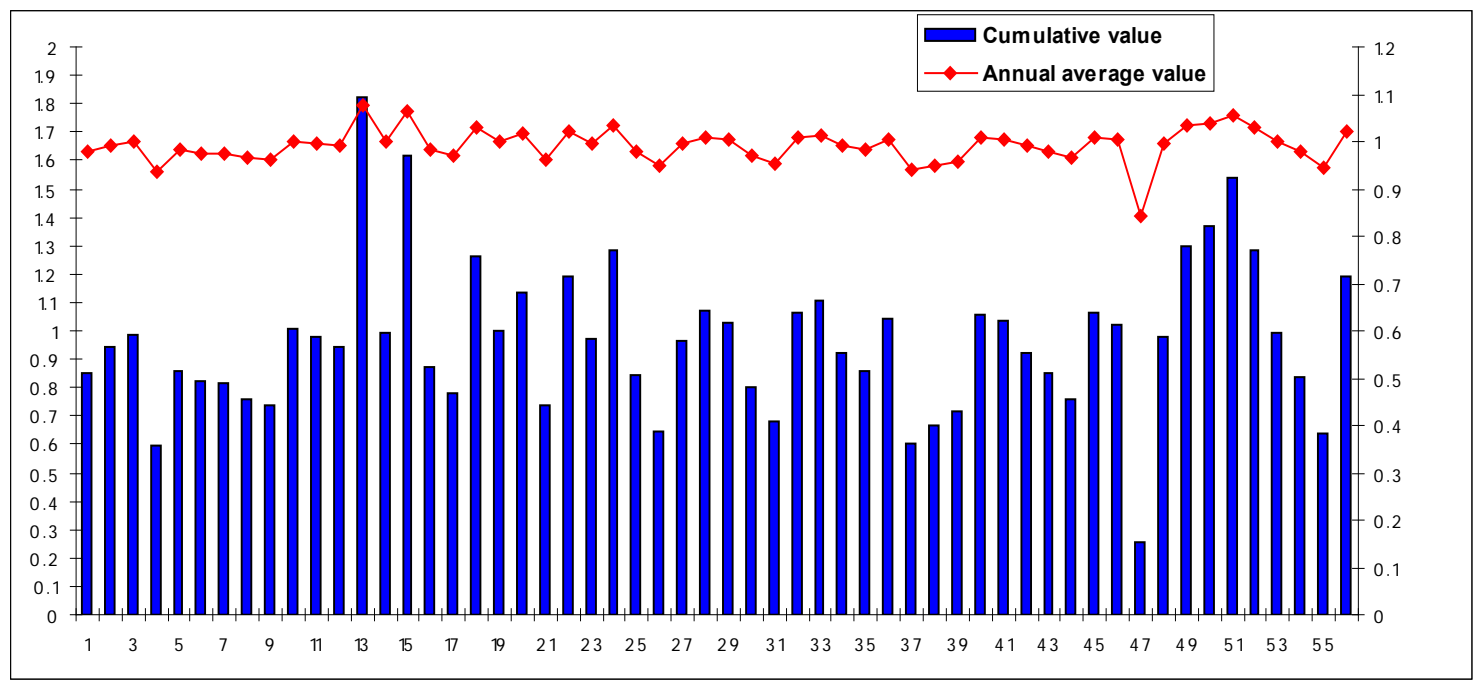

\subsubsection{Results analysis}

The TFP change was negative for the majority of the Portuguese WSS. It oscillated between a minimum of 0.5592 (WSS 4) and a maximum of 2.0139 (WSS 13). 33 WSS presented TFP negative changes, whereas 20 WSS displayed positive values. Table 2 shows the main statistical parameters, while Table 3 stresses the WSS distribution by TFP group. The TFP cumulative value was 0.9793, given the average value of the four index numbers, with extremes in the indexes of Paasche (0.9874) and Laspeyres (0.9719). The average value of the TFP drop was about $0.40 \%$ per year. Bearing in mind the population covered for each WSS, the TFP cumulative weighted average value was 0.9592 .

5 The WSS were sorted in descending order of population covered by service delivered. 
Table 2 - Major statistical results for the sample studied

\begin{tabular}{lccccc}
\hline Results & Average & St. deviation & Median & Minimum & Maximum \\
\hline Average values & 0.9960 & 0.0339 & 0.9977 & 0.9355 & 1.0914 \\
Cumulative values & 0.9793 & 0.2467 & 0.9703 & 0.5971 & 1.8224 \\
\hline
\end{tabular}

Table 3 - Distribution of WSS by TFP group

\begin{tabular}{llcccc}
\hline Group & WSS & WSS (no.) & Group & WSS & WSS (no.) \\
\hline$<0.6$ & 4,47 & 2 & $1.1-1.2$ & $18,20,33,56$ & 4 \\
$0.6-0.7$ & $26,31,37,38,55$ & 5 & $1.2-1.3$ & $22,24,49,52$ & 4 \\
$0.7-0.8$ & $8,9,17,21,39,44$ & 6 & $1.3-1.4$ & 50 & 1 \\
$0.8-0.9$ & $1,5,6,7,16,25,30,35,43,54$ & 10 & $1.5-1.6$ & 51 & 1 \\
$0.9-1$ & $2,3,11,12,14,23,27,34,42,48,53$ & 11 & $1.6-1.7$ & 15 & 1 \\
$1-1.1$ & $10,19,28,29,32,36,40,41,45,46$ & 10 & $>1.7$ & 13 & 1 \\
\hline
\end{tabular}

The productivity fall in this period is justified by different causes discussed below. Besides, it is important to stress two fundamental questions which were not included in the study. The first refers to the quality of service change and the second to the differences in the infrastructures aging.

The input index grew significantly during this period. There are, at least, three causes for that fact. The first refers to the decline in the input employees. While its change in quantities was reduced, the same did not happen in relation to the costs, whose rise was bigger than the consumer price index. The most qualified staff, the career progress rules, the higher training degree and the growing use of overtime had also contributed for this growth. The second cause regards the increase of the input other quantities of operation and maintenance. The huge investment in new nonexistent infrastructures brought about more operation and maintenance costs. Some WSS decided to import water and this led to higher costs in the water production. The evolution of the sector is also responsible for this input weakening, indicating not only stricter regulatory requirements (e. g. water quality and sewage discharge), but also a change in the customers and users' behavior, who complain and demand for better services. Finally, the third cause refers to the input capital, which grew almost exponentially. The high investment made in this period was mainly the result of the coverage level improvement, the building of assets necessary to the multimunicipal systems connection and the greater concern with the systems maintenance (e.g. rehabilitation).

In spite of growing less than the input index, the output index also presented an expressive rise. First, the larger number of people served by WSS assets, as an outcome of the population expansion and migration to areas of more population density. Second, the rise in the coverage level, specially the sewerage service. During this period, the water service coverage level rose from about $88 \%$ to $93 \%$ and the one of the sewerage service presented a rise from $63 \%$ to almost $77 \%$ for the 
WSS analyzed. At last, the living conditions improvement allowed for a higher water consumption and a higher number of families with an extra house.

\section{MALMQUIST PRODUCTIVITY INDEX}

\subsection{Advantages, definition and decomposition}

MPI has been gaining relevance over the past years with widespread applications. It is expressed in terms of distance functions and it can be either input or output oriented. ${ }^{6}$ Usually, the MPI computation is included in the non-parametric frontier methods, so it has nice features, such as: a) the absence of the production function behavioral assumption (e.g. minimum cost); b) its calculation can be grounded just in quantity data (MPI neither requires the input and output price values, nor their weights); c) the non-assumption of the WSS as efficient enables the separation of the productivity change, particularly into the TEC and PTC and of these, subsequently, into other components; and d) the ability that the MPI has to establish relationships with other indicators. It should also be stressed that the MPI is quick to compute, being based on the efficiency measures (inverse of Farrell's technical efficiency) obtained by linear programming techniques. As the main drawbacks, the MPI requires a panel data set and it is prone to atypical observations (outliers).

Caves et al. (1982) introduced two theoretical indexes, which were labeled as input and output MPI. These authors compare two input/output vectors concerning a reference technology by using the inputs or the outputs radial scaling, either for the input or output productivity indexes. Therefore, they defined the input-oriented MPI as:

$$
\operatorname{MPI}_{i}^{t}=\frac{D_{i}^{t}\left(y^{t+1}, x^{t+1}\right)}{D_{i}^{t}\left(y^{t}, x^{t}\right)}
$$

In (2), the period t technology is the reference technology, but it could be based on the period $\mathrm{t}+1$ technology. In order to avoid the adoption of a discretionary model, and in the spirit of Fisher index, an input-oriented MPI can be established as the geometric mean of two MPI of Caves et al. kind: ${ }^{7}$

MPI $=\left[\left(\frac{D_{i}^{t}\left(y^{t+1}, x^{t+1}\right)}{D_{i}^{t}\left(y^{t}, x^{t}\right)}\right)\left(\frac{D_{i}^{t+1}\left(y^{t+1}, x^{t+1}\right)}{D_{i}^{t+1}\left(y^{t}, x^{t}\right)}\right)\right]^{1 / 2}=\left(\frac{D_{i}^{t+1}\left(y^{t+1}, x^{t+1}\right)}{D_{i}^{t}\left(y^{t}, x^{t}\right)}\right) \times\left[\left(\frac{D_{i}^{t}\left(y^{t+1}, x^{t+1}\right)}{D_{i}^{t+1}\left(y^{t+1}, x^{t+1}\right)}\right)\left(\frac{D_{i}^{t}\left(y^{t}, x^{t}\right)}{D_{i}^{t+1}\left(y^{t}, x^{t}\right)}\right)\right]^{1 / 2}$

The first term on the right side of (3) measures the TEC between the periods $t$ and $t+1$, that is, the distance shift of the consumed inputs in relation to the minimum potential inputs allowable (i.e. catch-up). The ratio inside the square brackets stands for the PTC between the periods $\mathrm{t}$ and

6 The distance function (input oriented) is defined as opposite to the maximal proportional contraction (radial) of the inputs vector $\mathrm{x}^{\mathrm{t}}$ given the outputs $\mathrm{y}^{\mathrm{t}}$ consistent with the production technology $\mathrm{S}^{\mathrm{t}}$, that is: $\mathrm{D}_{\mathrm{i}}^{\mathrm{t}}\left(\mathrm{y}^{\mathrm{t}}, \mathrm{x}^{\mathrm{t}}\right)=\sup \left\{\lambda:\left(\mathrm{x}^{\mathrm{t}} / \lambda, \mathrm{y}^{\mathrm{t}}\right) \in \mathrm{S}^{t}\right\}$.

7 See Färe et al. (1989). 
$\mathrm{t}+1$. PTC can occur owing to an increase (or decrease) in the transformation ratio of the outputs, with or without changes in the proportion of the inputs consumed and outputs produced (i.e. innovation).

If production under constant returns to scale is taken into account, and admitting variable returns to scale, the TEC and the PTC can, in turn, be decomposed. ${ }^{8}$ TEC can be separated into a component due to scale efficiency change (SEC) and, into another, due to true technical efficiency change, called pure technical efficiency change (PTEC). ${ }^{9}$ SEC measures the deviation resulting from the adoption of constant returns to scale. PTEC can even be decomposed if congestion is assumed..$^{10}$ It can be subdivided into congestion efficiency change (CEC) and into "true" pure technical efficiency change (PTECC).

The MPI methodology adopted is based on constant returns to scale, whose TEC component is decomposed into SEC and PTEC, being this one divided into PTECC and into CEC. It presents several advantages stressed by Grosskopf (2003), such as to avoid converging computational problems when variable returns to scale and congestion are directly employed. Some authors refer that the MPI computed like this is only coincident with the TFP in particular situations. Besides, even for these, the results are biased to a small degree. ${ }^{11}$

\subsection{Case-study}

The MPI study encompassed a lower number of WSS, since in this technique the results of a particular entity depend on the remaining peers. So, 45 WSS (without the WSS that provide water supply) were studied, covering about $48 \%$ of the Portuguese population.

\subsubsection{Models specification}

In the MPI application the model orientation, the variables that should be adopted and the disaggregation level, as well as the kind of units chosen for measurement need to be considered carefully in its specification. Here the choice was for an input-oriented view. This is the most adequate for sectors subject to public service obligations (e.g. universality) and demand side management policies and whose main goal is not the profits distribution among shareholders.

The number of variables should be balanced, bearing in mind the sample and the production function key elements. The larger the WSS number is, the larger the number of variables that might be included will be and stronger will be the probability that the relative efficiency frontier has

8 PTC can also be decomposed. See Färe and Grosskopf (1996).

9 See Färe et al. (1998) for the decomposition of MPI.

10 Thus, it is possible that the production degree can decrease while one of the production factors increases. The congestion efficiency measures the effect that certain technological, regulatory or institutional factors have in some WSS, leading them to consume more inputs than their peers. This component specifies the additional reduction of inputs that can occur if there is no congestion.

11 MPI is identical to TFP when constant returns to scale and a production technology with single input and output exist. See Grifell-Tatjé and Lovell (1995) and Lovell (2003). 
to be near the real efficient frontier. However, the model must include the production chief aspects. The explanatory variables likely to justify the results might be integrated in a second stage. ${ }^{12}$

The variables can be represented in monetary or quantity units. The outputs are usually measured in quantities, since these units are more feasible and more intuitive. Besides, they do not need updating or monetary conversion, nor do they depend on each WSS tariff policy, even though there is no difference in the quality of the goods (or services) provided. The situation is more controversial with regard to the inputs. The main advantage of measuring the inputs in quantities is to avoid the differences in the costs accounting between WSS (e.g. depreciation) but, on the contrary, this does not reflect the differences in the inputs quality (e.g. assets aging) and causes great difficulties in the inclusion of all the inputs (e.g. vehicles and computers). The measurement done by means of monetary units enables us to capture all the inputs and their quality but it can raise equity problems. Because of that four distinct models were adopted, one whose inputs were based on monetary units (A), another on quantities (B), a third one also on monetary units (C) and a fourth model which was mixed $(\mathrm{D}) .^{13}$

The models applied comprised three outputs and three inputs displayed in Table 4. The inputs of model $\mathrm{C}$ are similar to the ones of model $\mathrm{A}$, considering, nevertheless, that the capital costs involve two parts, one concerning the depreciation plus interest expenses based on accounting elements and the other corresponding to the tangible assets rate of return assumed as being fair. In model A the capital costs are related to the sum of interest expenses plus depreciation. The net asset is taken from the account reports, whereas the rate of return adopted (capital cost) corresponds to a value resulting from the sum of the average Euribor of $3.5 \%$ plus a spread of $3 \%(6.5 \%)$.

Table 4 - Variables average values for the different models

\begin{tabular}{|c|c|c|c|c|c|c|c|}
\hline & 1994 & 2001 & Change & & 1994 & 2001 & Change \\
\hline Outputs Models A, B, C, D & & & $(\%)$ & Inputs Model C & & & $(\%)$ \\
\hline Revenue water volume $\left(10^{3} \mathrm{~m}^{3}\right)$ & 5264 & 6554 & 24.5 & Staff costs $\left(10^{3} €\right)^{*}$ & 2387 & 3010 & 26.1 \\
\hline WS customers (no.) & 36992 & 47269 & 27.8 & Other OPEX $\left(10^{3} €\right)^{*}$ & 2507 & 4204 & 67.7 \\
\hline SS users (no.) & 22254 & 31308 & 40.7 & Capital costs $\left(10^{3} €\right)^{*}$ & 1974 & 3410 & 72.7 \\
\hline Inputs Model A & & & & Inputs Model D & & & \\
\hline Staff costs $\left(10^{3} €\right)^{\star}$ & 2387 & 3010 & 26.1 & Staff costs $\left(10^{3} €\right)^{*}$ & 2387 & 3010 & 26.1 \\
\hline Other OPEX $\left(10^{3} €\right)^{*}$ & 2507 & 4204 & 67.7 & Other OPEX $\left(10^{3} €\right)^{*}$ & 2507 & 4204 & 67.7 \\
\hline Capital costs $\left(10^{3} €\right)^{*}$ & 1011 & 1633 & 61.5 & Mains and sewer (km) & 660 & 906 & 37.3 \\
\hline \multicolumn{8}{|l|}{ Inputs Model B } \\
\hline Staff (no.) & 184 & 198 & 7.6 & & & & \\
\hline Other OPEX $\left(10^{3} €\right)^{*}$ & 2507 & 4204 & 67.7 & * 2001 reference values & & & \\
\hline Mains and sewer (km) & 660 & 906 & 37.3 & & & & \\
\hline
\end{tabular}

WS - water service; SS - sewerage service

12 In the non-parametric techniques the presence of outliers is always a matter of major importance. If a particular water utility belongs to the frontier and is an outlier it will influence all the other results. In this research some care was taken in this analysis. See, about outliers, Wilson (1993).

13 Capital cost is always very troublesome to measure because the firms account it in different ways. In some cases here it was necessary to make some adjustments to increase the comparability. 


\subsubsection{Results}

Figure 3 shows the MPI cumulative results for the period considered by model and WSS, sorted in descending order of population covered. WSS 18 and 26 were adopted as outliers and taken out of the sample. The computation was done by a code created in GAMS.

Figure 3 - Results comparison of models A, B, C and D

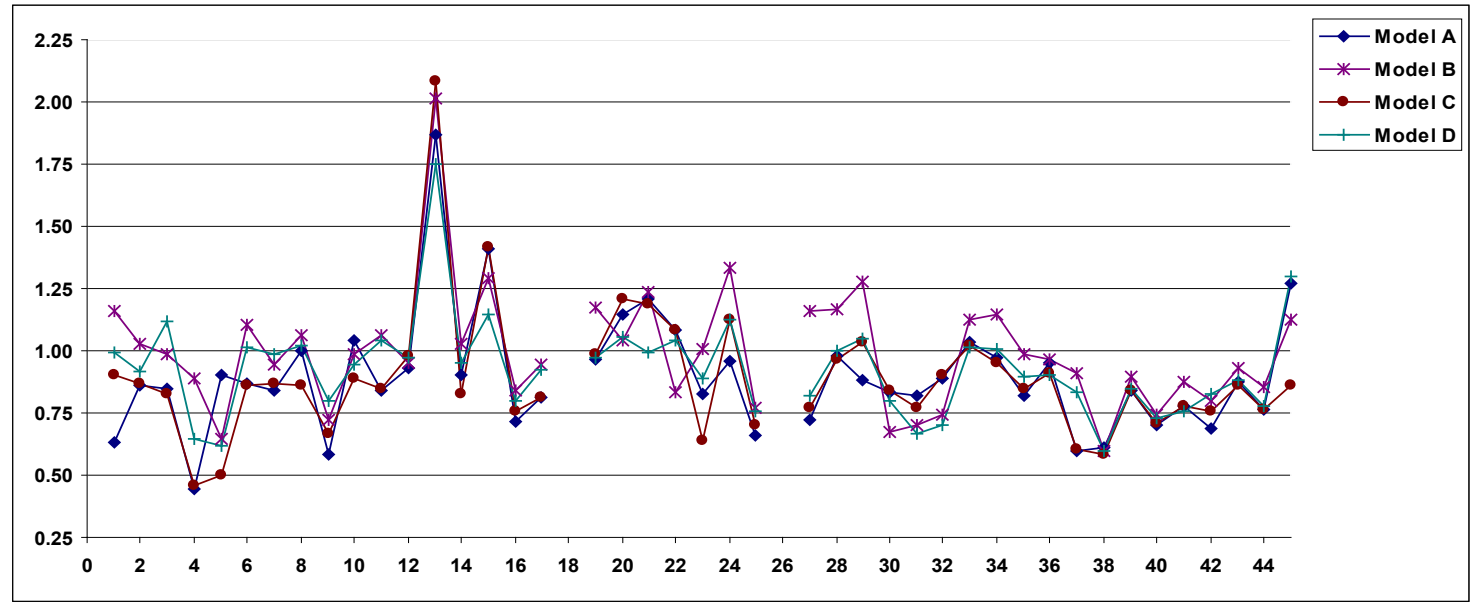

\subsubsection{Results analysis}

Over the period 1994-2001, the MPI annual average value was slightly inferior to 1 for models A, C and D with the respective values of $0.9845,0.9836$ and 0.9896 , and near the unit (0.9991) for model $\mathrm{B}$. The cumulative values were $0.8829,0.9886,0.8832$ and 0.9257 for models $\mathrm{A}, \mathrm{B}, \mathrm{C}$ and $\mathrm{D}$, correspondingly. The results favor the model in quantities if they are compared with the ones in monetary units, actually, as expected. The cumulative average productivity fell $11.7 \%$ for model A, $1.1 \%$ for model B, $11.2 \%$ for model C and $7.4 \%$ for model D. Table 5 provides the MPI decomposition results. Considering the four models average values, over the period analyzed, the loss in productivity was, chiefly, a result of the PTC negative change (around $9.8 \%$ ), that is, it was due to the lowest transformation rate of the inputs consumed into outputs. This deterioration can be justified by the rise of some quality parameters (e. g. sewage treatment). The SEC was also negative. It declined $1.2 \%$, meaning that proportionally there was an input consumption of more 1.2 $\%$ for the same production of outputs in 2001 than in 1994. Both PTECC and CEC had a positive participation in the productivity change. PTECC had the major part, with roughly $4 \%$, denoting that the WSS studied, on the whole, were nearer the efficient frontier in 2001 than in 1994. The part corresponding to CEC had a reduced influence on average, approximately, $0.4 \%$ and was only noticeable in a small number of WSS. 
Table 5 - Decomposition of MPI models with scale and congestion effects (cumulative values)

\begin{tabular}{lccccc}
\hline Model & SEC & PTECC & CEC & TEC & PTC \\
\hline A & 0.980 & 1.054 & 0.992 & 1.014 & 0.882 \\
B & 0.999 & 1.064 & 0.992 & 1.054 & 0.947 \\
C & 0.967 & 0.997 & 1.040 & 0.998 & 0.890 \\
D & 1.007 & 1.043 & 0.993 & 1.040 & 0.890 \\
\hline Global average & 0.988 & 1.040 & 1.004 & 1.027 & 0.902 \\
\hline
\end{tabular}

\section{RESULTS DISCUSSION}

\subsection{Productivity results comparison}

It would be desirable that the WSS productivity results were robust and equivalent, regardless of the technique adopted. Although both techniques are non-parametric and the models conception is done in a similar way, the MPI is a frontier method and that fact has obvious consequences. The index numbers scores reflect a lower penalization of the WSS when they are weighted against the MPI. This can be explained because the index numbers adopt market values as weights, instead of shadow values. In this technique the WSS are compared with themselves, while in the MPI the WSS are weighted against their peers located at the efficient frontier. This difference is more accentuated when the distance of cost minimization from reality is wider. This means that in sectors $(e$. $g$. water) where that worry sometimes is not noticeable there will be major differences. From another view, but in the same line, an improvement in the resources assignment (allocative efficiency) is integrated by the index numbers, but not by the MPI, which can be relevant as well. Figure 4 shows the high correlation between the different models. The lowest rank correlation coefficient is 0,573 (model B and index numbers) and the highest is 0,886 (models A and C).

Figure 4 - Cumulative annual results comparison between MPI models and index numbers

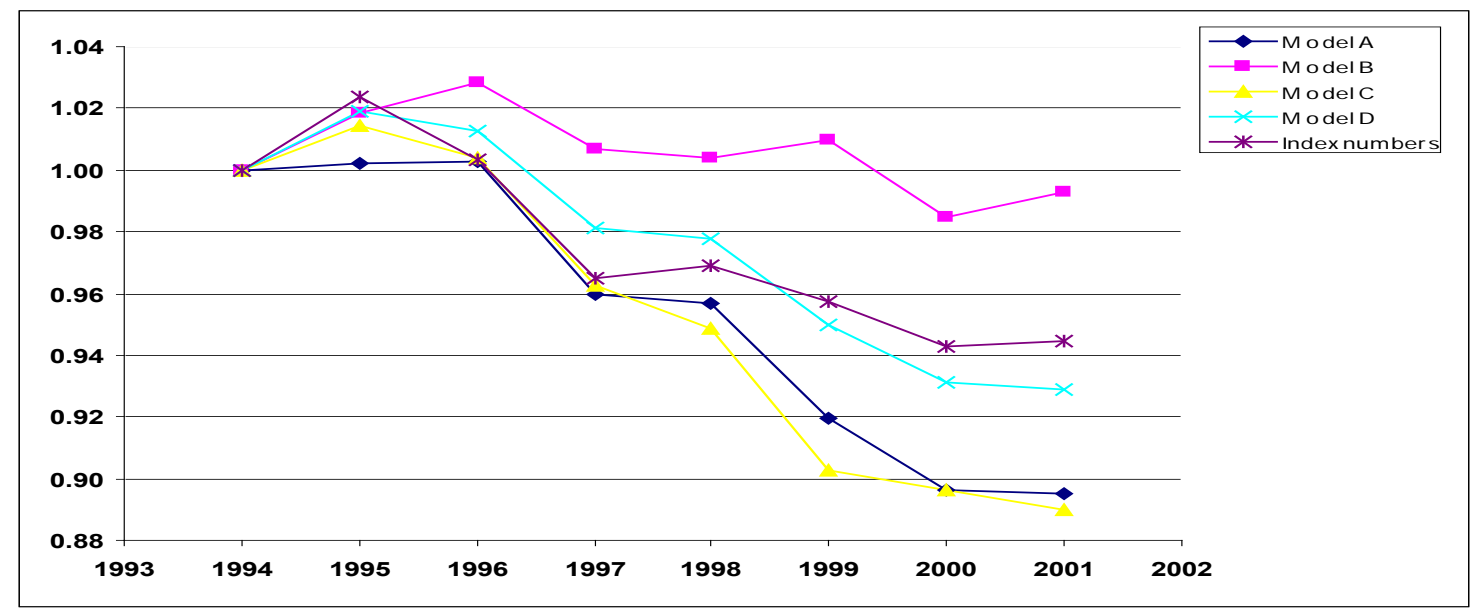




\subsection{Explanatory factors}

Neither the productivity results obtained by the index numbers, nor the ones obtained by the MPI are positive, although both of them fit what usually is mentioned for this sector in the specialized literature. The WSS, because of being monopoly industries with significant returns to scale and because of demanding intensive capital and long-lived assets, and often also sunk assets, do not add much incentive to efficiency and innovation and, consequently, to productivity. Besides, the consumption is almost inelastic and, from the environmental point of view, the incentive to increase the demand is not welcome. Nevertheless, the WSS productivity negative values in Portugal point to some mismanagement with regard to the staff cost and the capital costs, threatening their sustainability. For that reason, the WSS privatization has grown and has become more and more a recurrent subject as a result of the poor performance revealed. However, it is also true that the WSS reflect both an improvement in the quality of service, which was not weighed up, and high investments, especially in the sewage treatment. Confronted with the results, the WSS managers presented some justifications for the productivity change, mainly the WSS size and their social structure, the mode of organization, the coverage level and the quality of service, all of them discussed below. ${ }^{14}$

\subsubsection{Size and social structure}

The TFP average cumulative weighted value $(0.9492)$ is more restraining than the one not weighted (0.9654), conveying a penalization of the largest WSS. ${ }^{15}$ This effect is even stronger if we take into account the WSS social characteristics, for example, through their customers' density. Then, if the results are sorted into rural, semi-urban and urban, depending on whether their customers' number per mains length $(\mathrm{km})$ is less than 50 , between 50 and 125 or more than 125 , the rural WSS show, on average, a higher productivity progress, as expected. ${ }^{16}$

The correlation between the TFP of each WSS and the different variables representative of their size was measured and their relationship was statistically tested. Three measures of association and several statistical tests were applied. Except for the customers' density, all the correlation measures obtained and displayed in Table 6 are very reduced and stress a very low association degree. The negative values presented show an inverse change between the TFP and the variables analyzed.

14 The results presented refer only to the index numbers. Nonetheless, the ones regarding the MPI are similar on the whole, although some differences occur, depending on the sample size.

15 TFP were also weighted considering the outputs. The results attained kept the same trend.

16 See Marques and Monteiro (2001). It would be better to characterize the WSS social structure through the number of connections by mains length. Yet, these elements were not known to almost all the WSS. 
Table 6 - Bivariate correlation between the WSS TFP and their size

\begin{tabular}{|c|c|c|c|c|c|c|}
\hline \multirow{2}{*}{ Variable } & \multicolumn{2}{|c|}{ Pearson } & \multicolumn{2}{|c|}{ Spearman } & \multicolumn{2}{|c|}{ Kendall's tau-b } \\
\hline & Coefficient & Significan.* & Coefficient & Significan.* & Coefficient & Significan. ${ }^{*}$ \\
\hline Number of inhabitants & -0.082 & 0.559 & -0.067 & 0.631 & -0.033 & 0.724 \\
\hline Mains length & -0.025 & 0.857 & -0.010 & 0.944 & -0.005 & 0.957 \\
\hline Number of customers & -0.130 & 0.354 & -0.184 & 0.186 & -0.123 & 0.192 \\
\hline Customers' density & -0.224 & 0.106 & -0.333 & 0.015 & -0.219 & 0.021 \\
\hline
\end{tabular}

* two-tailed.

The second part of the analysis tried to test if the productivity change expected for each WSS set was identical, regardless of the set to which they belonged. In a first step, the reallocation of the customers' density was done into two groups, rural and urban, in accordance with the customers' number per km (less or more than 75). The tests adopted lead to the rejection of the hypothesis Ho. In a second step, the sample was split into three groups, which led to the adoption of other tests. It was possible to notice that all tests allowed for the rejection of the hypothesis Ho, at a significance level of $5 \%$, upholding the idea that the TFP evolution was penalizing in the WSS with more urban characteristics than in the most rural ones. Table 7 highlights the major results.

Table 7 - Hypotheses tests to the relation between the WSS TFP and their social structure

\begin{tabular}{llccc}
\hline Test & \multicolumn{1}{c}{$\mathrm{H}_{0}$} & Value & Crit. Value (5\%) & Decision \\
\hline $\mathrm{T}^{*}$ & Both groups present a similar TFP average & -2.05 & $-1.96(\mathrm{~N})$ & Reject $\mathrm{H}_{0}$ \\
Wilc. Mann-Whitney* & Both groups show the same central trend & -2.40 & $-1.96(\mathrm{~N})$ & Reject $\mathrm{H}_{0}$ \\
ANOVA & The TFP average does not depend on the social structure & 4.09 & $3.19(\mathrm{~F})$ & Reject $\mathrm{H}_{0}$ \\
Median & There is no TFP difference by social structure & 6.33 & $5.99\left(\mathrm{X}^{2}\right)$ & Reject $\mathrm{H}_{0}$ \\
Kruskal-Wallis & The three groups show the same central trend & 7.69 & $5.99\left(\mathrm{X}^{2}\right)$ & Reject $\mathrm{H}_{0}$ \\
\hline
\end{tabular}

* two-tailed.

\subsubsection{Mode of organization of the WSS}

The study analyzed the influence the WSS mode of organization had in the TFP change. On average, as Figure 5 shows, the TFP evolution was higher for the private companies and more negative for the municipal companies. 
Figure 5 - TFP cumulative change by WSS mode of organization

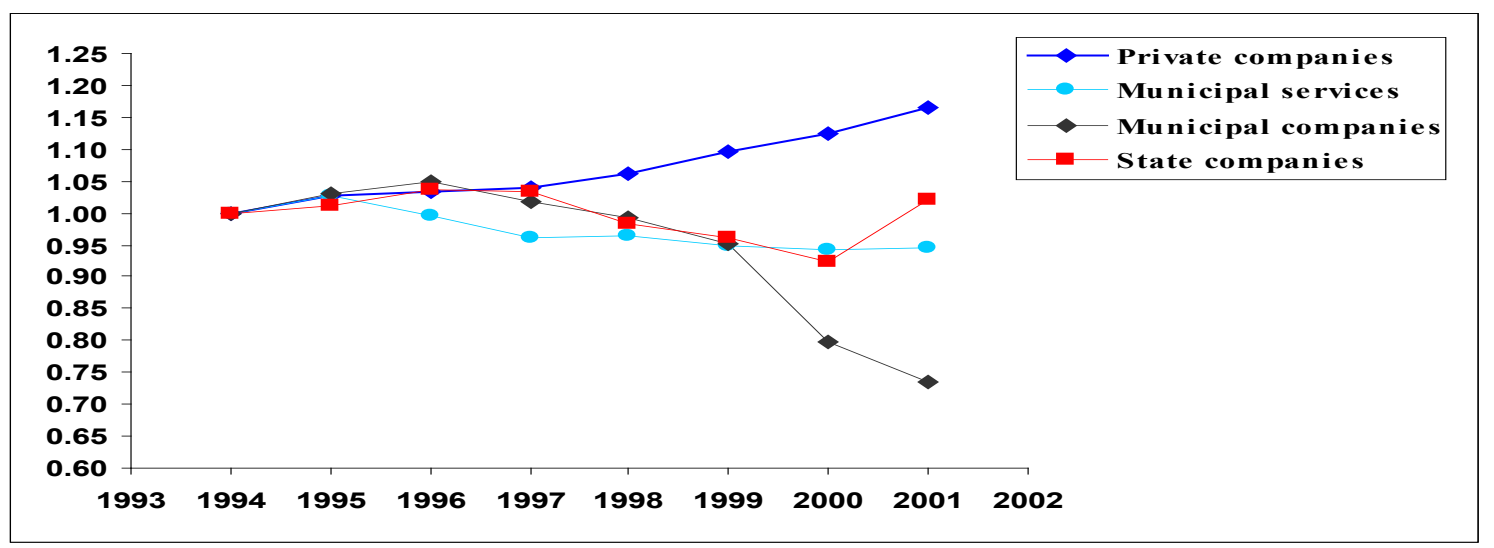

Table 8 presents the main statistical results of this analysis. In the statistical study several tests were carried out. The hypothesis tested through different statistical parameters was if there was difference between the TFP changes in the WSS by their mode of organization. Following the same methodology, the sample was divided into two groups, one for the private companies and another for the remaining modes of organization, and then into three groups, adding the municipal companies. Table 9 displays the results obtained. Thus, and in spite of some cautions related to the novelty of the private and municipal companies, it was concluded that the TFP change, in Portugal, has been influenced by the WSS mode of organization.

Table 8 - TFP results statistical summary by WSS mode of organization

\begin{tabular}{lccccc}
\hline Scenario & Average & St. Deviation & Median & Minim. & Maxim. \\
\hline Private company & 1.1800 & 0.3491 & 1.1914 & 0.7391 & 1.8224 \\
Municipal service with autonomy & 0.9459 & 0.1919 & 0.9656 & 0.6051 & 1.6146 \\
Municipal company & 0.7301 & 0.1306 & 0.7365 & 0.5971 & 0.8582 \\
State company & 1.0199 & 0 & 1.0199 & 1.0199 & 1.0199 \\
\hline
\end{tabular}

Table 9 - Hypotheses tests to the relation between WSS TFP and their mode of organization

\begin{tabular}{llccl}
\hline Test & \multicolumn{1}{c}{$\mathrm{H}_{0}$} & Value & Crit. value (5\%) & Decision \\
\hline $\mathrm{T}^{*}$ & Both groups present a similar TFP average & -2.17 & $-1.96(\mathrm{~N})$ & Reject $\mathrm{H}_{0}$ \\
Wil. Mann-Whitney* & Both groups show the same central trend & -2.18 & $-1.96(\mathrm{~N})$ & Reject $\mathrm{H}_{0}$ \\
ANOVA & The TFP average does not depend on the social structure & 5.50 & $3.19(\mathrm{~F})$ & Reject $\mathrm{H}_{0}$ \\
Median & There is no TFP difference by social structure & 2.81 & $5.99\left(\mathrm{X}^{2}\right)$ & Accept $\mathrm{H}_{0}$ \\
Kruskal-Wallis & The three groups show the same central trend & 6.35 & $5.99\left(\mathrm{X}^{2}\right)$ & Reject $\mathrm{H}_{0}$ \\
\hline
\end{tabular}

* two-tailed. 


\subsubsection{Coverage level of the WSS}

The study also analyzed whether or not the increase in the WSS coverage level interfered with the TFP change. A bivariate correlation analysis was done, always pointing to a very low association degree. When comparing the TFP between the WSS it is necessary to bear in mind that the development measure was not equal to all of them and this might have been decisive to get the TFP scores. Anyway, this reality is, in part, counterbalanced by the output index growth, which followed the same trend of the investment needed to the increase in the coverage level.

Analyzing the problem from a different perspective, by grouping the WSS into three classes, depending on whether the coverage level grew in the period considered less than $1 \%$, between 1 and $3 \%$, or more than $3 \%$ per year, for each service (water and sewerage), it was attested that the TFP change seemed to be more unfavorable to the WSS with a higher growth of the coverage level, although without a significant correlation. Several tests were taken with the aim of rejecting that hypothesis, following the methodology referred above. All the tests were accepted at a $5 \%$ significance level. The results corroborate the acceptability of the TFP average evolution indifference hypothesis, according to the coverage level change.

\subsubsection{Quality of service and infrastructures aging}

The TFP change can be related to the quality of service oscillation. This study tried to include it in the TFP change computation. It intended to prove that the TFP drop between 1994 and 2001 was, in some way, the result of its improvement. Due to lack of elements, it was not possible to do that for most of the WSS. Even so, the TFP change was correlated with the indicators number of failures in the water mains and number of blockages in the sewers collected for the year 2001 for some WSS as a proxy of the quality of service. Figure 6 shows one of those associations.

\section{Figure 6 - Relation between TFP and indicator number of failures by mains length}

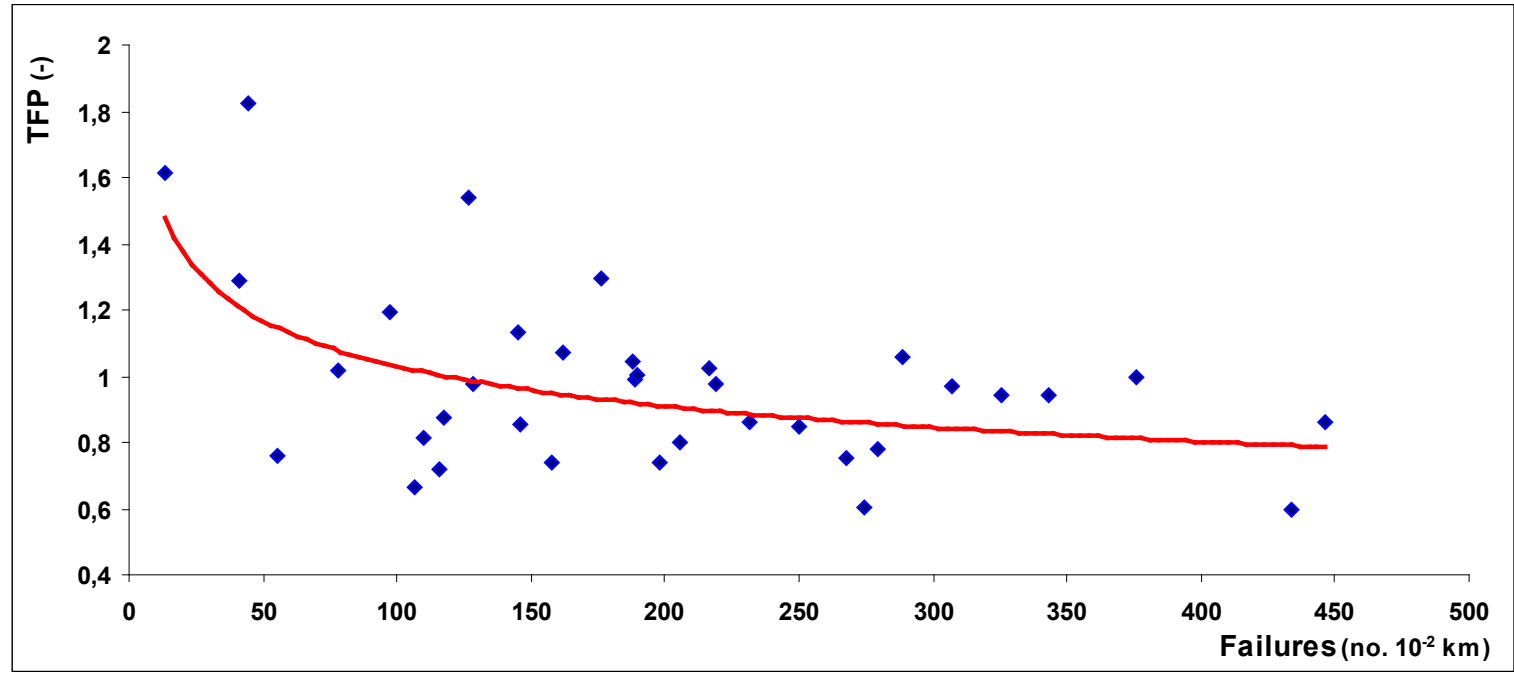


A regression analysis was done by taking into account the TFP evolution as the observable dependent variable and the number of failures and blockages as independent variables. The variance analysis rejected the hypothesis that the adjustment was not significant. Next, the correlation measures between these variables and the TFP evolution were computed, which proved the existence of an association degree from weak to moderate. The significance obtained allows us to reject that the correlation is equal to zero for all the tests at a level of $5 \%$. The hypotheses tests were also done to prove that the TFP was influenced by the indicators referred. Table 10 depicts the results, considering just two classes ( $>$ or $<250$ failures per $10^{-2} \mathrm{~km}$ and $>$ or $<300$ blockages per $10^{-2} \mathrm{~km}$ ). The results were not conclusive, but they let us accept the hypothesis with a $5 \%$ level.

Table 10 - Significance test between the WSS TFP and the numbers of failures and blockages

\begin{tabular}{|c|c|c|c|c|}
\hline Variable & Test $^{*}$ & $\mathrm{H}_{0}$ & Value & Decision (5\%) \\
\hline \multirow{2}{*}{ Failures } & Test T & Both groups present a similar TFP average & -2.33 & Reject $\mathrm{H}_{0}$ \\
\hline & Wil. Mann-Whitney & Both groups show the same central trend & -1.53 & Accept $\mathrm{H}_{0}$ \\
\hline \multirow{2}{*}{ Blockages } & Test T & Both groups present a similar TFP average & -1.95 & Accept $\mathrm{H}_{0}$ \\
\hline & Wil. Mann-Whitney & Both groups show the same central trend & -1.78 & Accept $\mathrm{H}_{0}$ \\
\hline
\end{tabular}

* two-tailed.

Summing up, it can be observed that the TFP progress is higher in the WSS with best performance for the indicators analyzed. The WSS whose assets are poor are the least productive. From another perspective, the assets quality can be pointed as the main reason for the TFP deterioration, being the result of a past history and not of the WSS present management. If that is real, it is also true that the productivity future earnings, at least in the medium and long term, will be higher in these WSS.

\subsection{Policy implications}

TFP calculation through different methods has shown negative values for the water sector in Portugal. This situation is partially justified by the improvement in the quality of service and the environmental quality which were not incorporated in the study but that have greatly improved over the last years. ${ }^{17}$ The results, however, are not uniform among operators. The private operators are more productive than the public ones, even though the former are regulated and the latter are not. The quality of service is also generally higher in the private companies. ${ }^{18}$ The supremacy of the private companies might not be related to the ownership but to the fact that, unlike the others, these are regulated. According to the Portuguese law only concessionary entities (private companies) are subject to economic and quality of service regulation. The regulatory method adopted by IRAR uses a sunshine regulation approach which has brought very positive benefits to the sector. Sunshine regulation is based on the comparison, public display and discussion of the operators' performance. ${ }^{19}$ IRAR uses a set of performance indicators, provides reference values and attributes scores

17 See the website of the regulator (www.irar.pt). The improvements are especially exceptional regarding the quality of water for human consumption.

18 See, for a comparison between the Portuguese private and public water utilities, Marques (2008).

19 See Marques (2006) for a discussion on the Portuguese yardstick competition regulatory method. 
by means of three colored balls, green, yellow and red depending on the operators' performance classification. This name and shame benchmarking strategy has revealed itself very effective.

TFP calculation, however, has several advantages, especially in the scope of economic regulation, in particular to determine prices and tariffs. In Portugal the public operators raise tariffs without any economic justification. They generally use the consumer price index to update the prices when they do not opt for a worse or for any methodology. TFP determination could be used to curb rises in the tariff systems. These regulatory policy adopted in other countries in the water sector (e. g. Australia) and in other sectors in Portugal (e. g. transportation) when price cap formulas (CPI-X) are used could be also adopted in Portugal, at least until IRAR has competencies over the public operators. It could be a way to set rules and simultaneously to provide incentives to the water utilities.

\section{CONCLUSIONS}

The aim of this document was to measure and discuss the WSS productivity change in Portugal. Two TFP techniques were used for this purpose. The TFP enables the assessment of the WSS economic performance by measuring the change of the total outputs produced in relation to the inputs consumed. It is a powerful tool with multiple goals whose use should be instigated in the water sector.

The index numbers technique is very easy and very prompt, requiring only one WSS. The results are transparent and easy to interpret, nevertheless the method does not enable the productivity decomposition. Moreover, this technique only takes into account the WSS under analysis, disregarding all the others, and demands elements about the quantities and prices both of inputs and outputs. The TFP change in Portugal, over the 1994-2001 period, was negative for the sample studied. It fell near $0.4 \%$ per year, corresponding to more than $2 \%$. The TFP decline can be partially justified by the service delivered improvement (e.g. sewage treatment).

The MPI method does not require a behavioral assumption such as cost minimization or profit maximization, neither does it need to know the inputs and outputs values in monetary units, nor their weights. This method also allows for the productivity decomposition. However, it demands a large number of WSS, its computation is more complex and the results interpretation offers more difficulties. The models results kept the negative trend of the Portuguese WSS productivity. Except for model B, all the others presented more negative results than the ones obtained by the index numbers. The negative results are primarily due to PTC. The SEC was also negative in this period, but to a lesser extent. On the other hand, both PTECC and CEC were positive. The greater contribute came from PTECC.

The index numbers results were compared with those attained by the MPI. The extreme values attained and the results general trend proved consistency between these models. The slightly discrepant values depicted can be, somehow, explained by the differences between the methods category. 
This document also analyzed the association between the WSS TFP scores and the various variables capable of justifying the performance obtained. It further examined statistically the TFP relationship with the WSS size and their social structure, mode of organization, population coverage level and quality of service. From this study it was concluded that the size or the social structure, represented by the customers' density, was significant at a level inferior to $5 \%$ and that the results were not indifferent from the mode of organization. Overall the private WSS were more productive for the level referred. In addition, the rise in the population coverage level was not statistically relevant and the WSS with better quality of service presented a higher TFP.

Finally, this paper highlights the importance of TFP in the economic regulation of water utilities.

\section{REFERENCES}

ABRAMOVITZ, M. Resource and output trends in the United States since 1870. American Economic Review, v. 46, n. 2, p. 5-23, 1956.

ACT. ACTEW benchmarked. In: Report, 7. Canberra: Auditor General's Office, 1995.

ANCARANI, A. Evolution of water firms performance in providing water services in Sicily. Proceedings of the EIASM International Conference on Accounting, Auditing \& Management in Public Sectors Reform, Saragossa, 2000.

ASHTON, J. Total factor productivity growth and technical change in the water and sewerage industry. The Services Industries Journal, v. 20, n. 4, p. 121-130, 2000.

CAVES, D.; CHRISTENSEN, L.; DIEWERT, E. The economic theory of index numbers and the measurement of input, output, and productivity. Econometrica, v. 50, n. 6, p. 1393-1414, 1982.

COELLI, T.; WALDING, S. Performance measurement in the Australian water supply industry: a preliminary analysis. In: NINTH EUROPEAN WORKSHOP ON EFFICIENCY AND PRODUCTIVITY ANALYSIS, 2005, Brussels.

CRAMPES, C.; ESTACHE, A.; DIETTE, N. What could regulators learn from yardstick competition? Lessons for Brazil's water and sanitation sector. Washington D.C.: World Bank, 1997.

DIEWERT, E. Fisher ideal output, input, and productivity indexes revisited. Journal of Productivity Analysis, v. 3, n. 3, p. 211-248, 1992.

ESTACHE, A.; KOUASSI, E. Sector organization, governance, and the inefficiency of African water utilities. In: Policy Research Working Paper, 2890. Washington D. C.: World Bank, 2002.

ESTACHE, A.; TRUJILLO, L. Efficiency effects of privatization in Argentina's water and sanitation services. Water Policy, v. 5, n. 4, p. 369-280, 2003.

EUROPE ECONOMICS Scope for efficiency improvement in the water and sewerage industries - report for Ofwat by Europe Economics. Birmingham, 2003. Report Commissioned by Office of Water Services.

FÄRE, R.; GROSSKOPF, S. Intertemporal production frontiers: with dynamic DEA. Boston: Kluwer Academic Publishers, 1996.

FÄRE, R.; GROSSKOPF, S.; ROOS, P. Malmquist productivity indexes: a survey of theory and practice. In: FÄRE, R. GROSSKOPF, S.; RUSSELL, R. Index numbers: essays in honour of Sten Malmquist. Boston: Kluwer Academic Publishers, 1998. 
FÄRE, R.; GROSSKOPF, S.; LINDGREN, B.; ROOS, P. Productivity developments in Swedish hospitals: a Malmquist output index approach. In: Discussion Paper Series, 89. Carbondale: Southern Illinois University at Carbondale, 1989.

GLASER, J. Multifactor productivity in the utility services industries. Monthly Labor Review, v. 116, n. 5, p. 34-49, 1993.

GRIFELL-TATJÉ, E.; LOVELL, K. A note on the Malmquist productivity growth index. Economic Letters, v. 47, n. 2, p. 169-175, 1995.

GROSSKOPF, S. Efficiency and productivity. In: FRIED, H.; LOVELL, R.; SCHMIDT, S. The measurement of productive efficiency: techniques and applications, Oxford: Oxford University Press, 1993.

. Some remarks on productivity and its decomposition. Journal of Productivity Analysis, v. 20, n. 3, p. 459-474, 2003.

HARCHAOUI, T.; DACHRAOUI, K. Water use shadow prices and the Canadian Business sector productivity performance. In: NINTH EUROPEAN WORKSHOP ON EFFICIENCY AND PRODUCTIVITY ANALYSIS, 2005, Brussels.

LIN Service quality and prospects for benchmarking: evidence from the Peru water sector. Utilities Policy, v. 13, n. 3, p. 230-239, 2005.

LONDON ECONOMICS; BLACK \& VEATCH CONSULTING; SHUTLER, M. PR04 - scope for efficiency studies. Uncertainties and measurement issues. Birmingham, 2003. Report commissioned by Office of Water Services.

LOVELL, K. The decomposition of Malmquist productivity indexes. Journal of Productivity Analysis, v. 20, n. 3, p. 437-458, 2003.

MANNING, I.; MOLYNEUX, E. Measurement of total factor productivity in major water utilities: Melbourne case study. In: Research Report, 65. Melbourne: Urban Water Research Association of Australia, 1993.

MARQUES, R.; MONTEIRO, A. Application of performance indicators in water utilities management - a case-study in Portugal. Water Science \& Technology, v. 44, n. 2/3, p. 95-102, 2001.

MARQUES, R. A yardstick competition model for portuguese water and sewerage services regulation. Utilities Policy, v. 14, n. 3, p. 175-184, 2006.

MARQUES, R. Comparing private and public performance of portuguese water utilities, Water Policy, v. 10, n. 1, p. 25-42, 2008.

NAKAYAMA, N. Efficiency and productivity of water utilities in Hyogo prefecture. Studies in Regional Science, v. 32, n. 3, p. 161-174, 2002.

NERA. Estimating OPEX and CAPEX efficiency. London, 2004. Report Commissioned by Water UK.

PARKER, D.; SAAL, D. Productivity and price performance in the privatized water and sewerage companies of England and Wales. Journal of Regulatory Economics, v. 20, n. 1, p. 61-90, 2001.

SAAL, D.; PARKER, D. The comparative impact of privatization and regulation on productivity growth in the English and Welsh water and sewerage industry: 1985-1999. International Journal of Regulation and Governance, v. 4, n. 2, p. 139-70, 2004.

. Assessing the performance of water operations in the English and Welsh water industry: a panel input distance function approach. In: Research Paper, 0502. Birmingham: Aston Business School, 2005.

SEROA DA MOTTA, R.; MOREIRA, A. Efficiency and regulation in the sanitation sector in Brazil. In: Texto para Discussão, 1059. Rio de Janeiro: Institute of Applied Economic Research, 2004. 
STEERING COMMITTEE. Measuring the total factor productivity of government trading enterprises. Canberra: Steering Committee on National Performance Monitoring of Government Trading Enterprises, 1992.

STONE \& WEBSTER CONSULTANTS. An investigation into OPEX productivity trends and causes in the water industry in England \& Wales - 1992-93 to 2002-03. Birmingham, 2004. Report commissioned by Office of Water Services.

WILSON, P. Detecting outliers in deterministic nonparametric frontier models with multiple outputs. Journal of Business and Economics Statistics, v. 11, n. 3, p. 319-323, 2004.

WOODBURY, K.; DOLLERY, B. Efficiency measurement in Australian local government: the case of NSW municipal water services. In: Working Paper, 13. Armidale: University of New England, 2003. 